\title{
The Memory of Colour: Havana Divas, Cantonese Opera
}

\section{S. Louisa Wei}

$\underline{\text { https://doi.org/10.15664/fcj.v0i17.2083 }}$

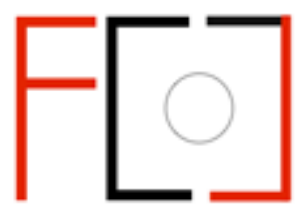

Frames Cinema Journal

ISSN 2053-8812

Issue 17 (Jun 2020)

(c) $\underset{\mathrm{EY}}{(1)}$

http://www.framescinemajournal.com 


\section{The Memory of Colour: Havana Divas, Cantonese Opera S. Louisa Wei}

The Cuban capital, Havana, is a city vibrant with colours. Walls of houses may be dilapidated, but the colours make the streets photogenic. The decayed spectacle recalls a prosperous past, before the U.S. imposed embargos on the island (around 1960). Havana has never failed to impress its visitors, whose initial sensory experience of the urban landscape begins with a unique palette of pink, beige, turquoise, and light-blue.

When my film crew first arrived in Havana in January 2015, we did not know that the small Chinese-Cuban community was preparing to celebrate the $170^{\text {th }}$ anniversary of the first Chinese to arrive in Cuba. ${ }^{1}$ Havana's Barrio Chino - one of the oldest Chinatowns in America (but without many Chinese) - showed signs of revival. The new Chinese restaurant quarter injected a cluster of Chinese red, golden-yellow, and emerald-green into the city's heart. These three colours stand out amidst the surrounding lighter colours of pink, beige, turquoise, and light-blue, leading us to explore a question that Umberto Eco asks but cannot answer, "how culture conditions the colours we see?" In his writing, Eco affirms that colours are a very "private affair" and that their meaning is more puzzling than other signs because languages simply fail to describe them. ${ }^{2}$

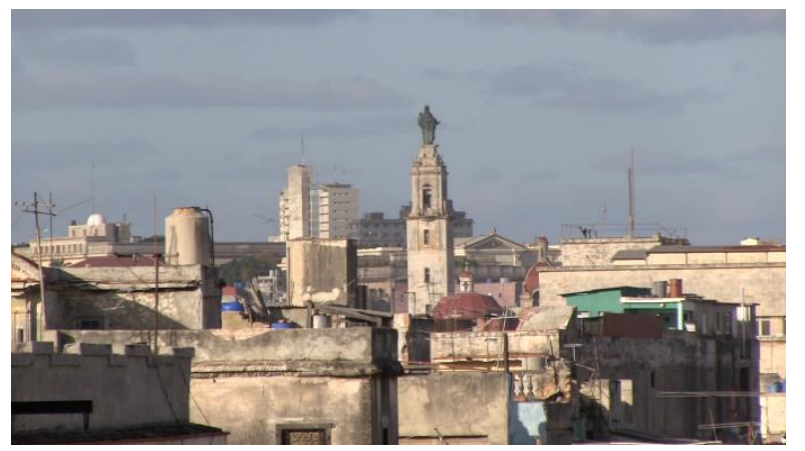

Figure 1: Havana cityscape from a rooftop taken in January 2015.

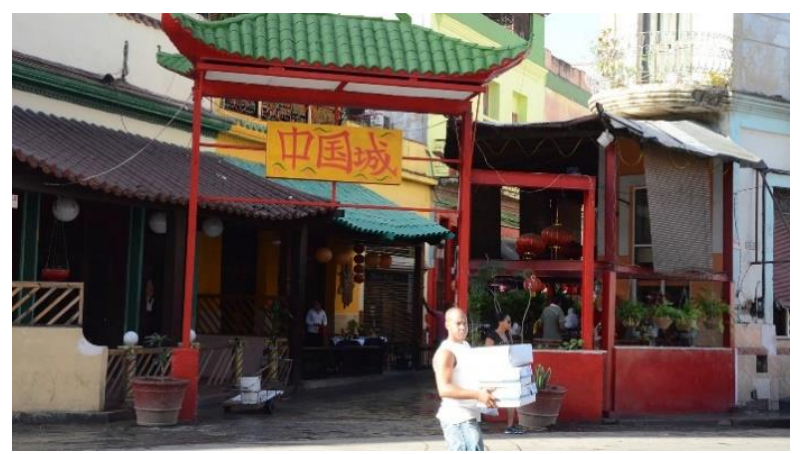

Figure 2: Havana’s Chinese restaurant quarter in January 2015, the yellow plate with three Chinese characters meaning Chinatown was relatively recent.

I find colour a natural point of departure when filming on location and a useful umbrella concept to understand an unfamiliar culture. This film featurette reflects upon the making of the documentary Havana Divas (2018), from the initial encounter of colours in filming to later research that led to critical decisions in postproduction. ${ }^{3}$ The film depicts the lives and times of two Cuban women - Caridad Amaran (1931-) and Georgina Wong-Gutiérrez (1929-), spanning from the 1930s to 2019. Caridad was born to white Cuban parents but raised by her mother, Josefa Amaran, and a Chinese foster father, Julian Fong. Georgina was the daughter of Afro-Cuban woman, Juana 
Gutiérrez, and Chinese man, Alfredo Wong. Caridad and Georgina learned Cantonese Opera in 1930s' Havana and toured Cuba in the 1940s. Caridad was the star of her opera troupe, who played buadan (or sassy, young, female) roles. Georgina's kungfu skills allowed her to play male warrior roles, but she left opera early for college. Although Fidel Castro's 1959 revolution and compulsory military service interrupted Georgina's study, she eventually became a diplomat. Caridad worked as a cashier after 1959.

Following their retirement, Caridad and Georgina began practicing Cantonese opera again. Between 2011 and 2019, they received sponsorship to make three trips to the origin of their art Canton, or Hong Kong and Guangdong Province of China - and reconnect with the culture their Chinese fathers came from.

The following discussion will reveal how colour was mediated through their memories, changing cultural identities, and toning technologies in digital filmmaking. Havana Divas was mainly shot on digital video cameras, but it includes a lot of old photos and stock footage shot on celluloid and video processed in digitised forms. Unless otherwise noted, all images illustrating this article are stills from the documentary.

\section{Cuban Divas of Cantonese Opera}

The historical background of Havana Divas is complicated, but can be understood through two parallel aspects. The first, regarding the early Chinese immigrants that formed the audience base for Cantonese Opera in Cuba, and the second, concerning the route and modes of performances by travelling opera troupes from Canton.

Between 1847 and 1874, about 125,000 to 150,000 indentured Chinese men arrived in Cuba to replace vacancies left behind by freed black slaves. ${ }^{4}$ They were called "coolies" - a word adopted from Chinese, meaning "hard labours". Nearly all of them were from Canton, a term referring to both Hong Kong and Guangdong Province of China today, where Cantonese Opera originated. As Cuban historians Mauro Garcia Triana and Pedro Eng Herrera describe, from 1860 to 1875 , many Chinese fled from the U.S. to Cuba "to escape new anti-Chinese laws and general Sinophobia." The wealthy newcomers were called "the Californians" in Cuba. They formed the foundation of Barrio Chino, and as Garcia and Herrera note, "hired Chinese laborers freed from their indentures to work in their enterprises." When Caridad's foster father, Julian Fong, and Georgina's father, Alfredo Wong, arrived Havana in the 1920s, they respectively worked as a laundryman and a tailor in Barrio Chino. Even though Cuba's Chinese population dropped from 60,000 to 30,000 from the early 1920 s to the mid-1930s, there was still enough interest in, and a good audience for, Cantonese Opera. ${ }^{6}$

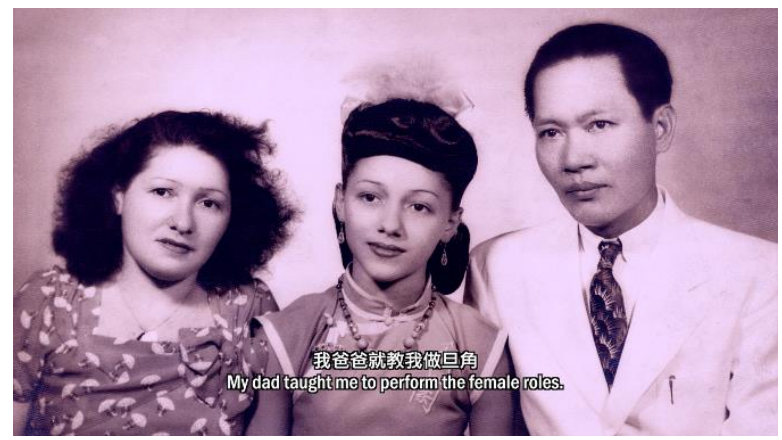

Figure 3: Caridad (centre) was with her mother Josefa Amaran and her foster father Julian Fong around 1939, when she began to perform with Kuoc Kong Company. 


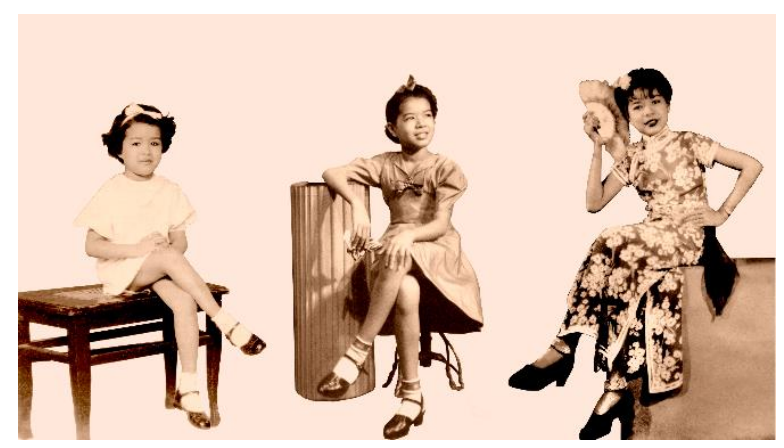

Figure 4: Georgina in dresses made by her father, who was a famous dressmaker in Barrio Chino, respectively taken c. 1935, 1939, and 1942.

The history of Chinatown Cantonese Opera in North America can be traced back to the 1852 performance by the Hong Fook Tong troupe's debut in San Francisco, which was followed by a string of theatres built for Cantonese Opera. ${ }^{7}$ Since then, travelling troupes from Canton would visit cities with Chinese communities, often stopping over in Hawaii, California, British Columbia, Ontario, New York, and even Cuba. ${ }^{8}$ As early as 1875, Cantonese Opera actors had already performed in Cuba, and a Canton-style theatre was built on in Cienfuegos, a city to the east of Havana. The next year, a troupe of " 94 Chinese artists" performed at the opening of Teatro de los Chinos.' A traveling troupe consisted of at least forty people, so contracting them to perform needed an enormous budget.

When Caridad's foster father, Julian Fong, and his friends organised Kuoc Kong Company in 1939 to teach and perform Cantonese Opera, they were making a home for opera in Havana so that they later would only need to hire a few stars instead of a whole troupe. When visiting stars were in town, the local company supplied musicians and actors to play minor roles. Thus, after these visiting stars would leave, the local company could continue entertaining its audience. Australian-born conductor Erich Kleiber (1890-1956) made the following comments after watching an opera in Havana's Chinese Theatre,

"They have some professional actors and, what is even more interesting, daughters of Chinese, Cuban by birth. These compatriots of ours, with slightly almond-shaped eyes, connoisseurs of great historical and legendary cycles, declaim in Chinese for four hours at a time, sing traditional arias, and perform with exquisite elegance the symbolic gestures that accompany action in Asian theater." 10

Since most girls could not speak Cantonese, the company maestros had to drill them very hard to get the pronunciation right. They learned a new play every week and performed over the weekends in collaborating theatres, including Shanghai Theatre, Golden Eagle, and New Continent Theatre. 


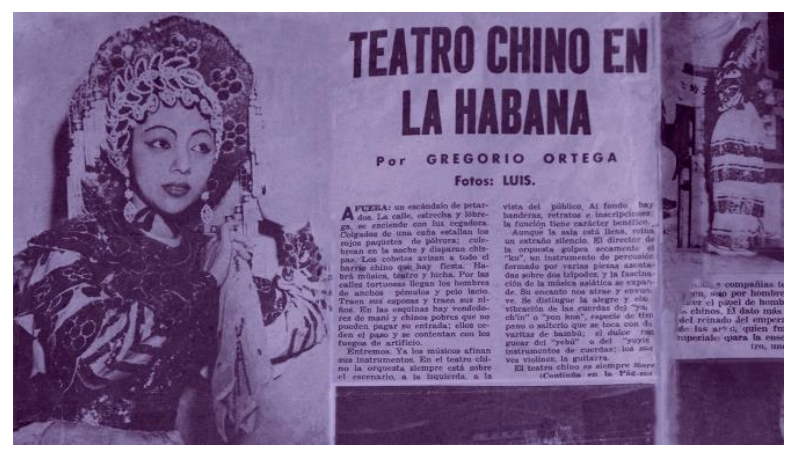

Figure 5: Caridad's image in a local newspaper's feature article, c. 1947.

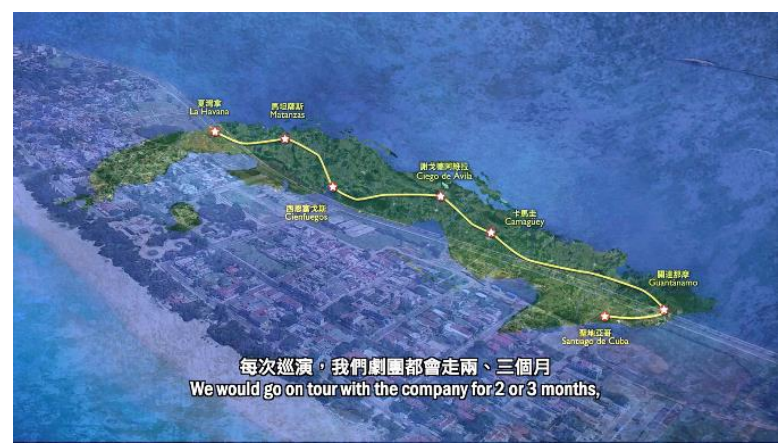

Figure 6: Cuban cities that Kuoc Kong divas toured: Matanzas, Cienfuegos, and Ciego de Avila, Camaguey, Guantanamo, and Santiago de Cuba.

In its heyday, Kuoc Kong had twenty actors, a dozen musicians, a few maestros, and even a costume maker. Caridad, who diligently learned to write and read in Chinese, was able to sustain her career as an opera diva for ten years. She was the only buadan in Kuoc Kong, who was good enough to play important roles on the same stage with the visiting stars. Limited by her language skills, Georgina mainly played supporting roles and dropped out early. When other stage sisters passed in old age or disease, she was the only one left who could play male roles and who could be paired up with Caridad. Kuoc Kong's fame soon spread throughout Cuba, and the company received invitations from other cities during the 1940s and into the early 1950s. Kuoc Kong closed in 1957, shortly after Caridad's wedding, which took place during the last visit of opera stars - this time from Honolulu. ${ }^{11}$ By this time, the opera girls were in their late twenties and had to take up responsibilities as grown women. Fidel Castro's revolution in 1959 put the comfortable and bohemian life of the Chinese community to an end. Caridad became a cashier in a Chinese restaurant. An episode Caridad shares in the film, and in other interviews, is that one day when Castro came to dine, he was impressed by how she could easily translate the Chinese menu into Spanish. Georgina graduated from college and then worked in the foreign affairs bureau. Meanwhile, wealthy Chinese-Cubans moved to other countries in fear of communism, causing the Barrio Chino to quickly decline, and the Cantonese Opera to lose its audience.

\section{Chinese Colours and the Opera Look}

Within the cultural-historical context laid out above, I will address Eco's question of -"how culture conditions the colour we see" - in the following discussion. Among all colours, the chinese-reds and golden-yellows are believed to offer a distinct and exotic visual experience unique to China. Danish architect Jørn Utzon, for instance, was so taken by these "imperial colours" during his 1958 visit to the Forbidden City, in Beijing, that he applied them to his designs for the Major Hall 
of the Sydney Opera House. ${ }^{12}$ With these colours, he writes, the halls "will form another world a make-believe atmosphere, which will exclude all outside impression[s] and allow the patrons to be absorbed into the theatre mood." "13 Chinese-red, golden-yellow, and emerald-green decorate Barrio Chino's restaurant quarter and characterise many other Chinatowns around the world. The visual impact felt by Utzon was also reflected by early western spectators of Chinese Opera in San Francisco, New York, Havana, London, and Singapore, since the mid-1800s, as opera offers an enriched palette of colours. ${ }^{14}$ Kleiber describes the actors as "sumptuously adorned" and the theatre "a world of wonders", stating that if "there is a crisis in our theater, the Barrio Chino is clearly unaware of it!" ${ }^{15}$ Watching an opera in Vancouver in the 1940s, Wayson Choy felt "a burst of color struck" his eyes when the "door size curtain parted", and when the actors came on stage "in sequined costumes of forest green and gold, jolting cobalt blue and fiery red, living myths swayed onto the stage, their swords slashing the air, their open ornate fans snapping." 16

Traditional Chinese colour symbolism is built around five colours representing the five essential elements of the universe - white for metal, green for wood, black for water, red for fire, and yellow for earth. Moreover, these five colours respectively govern the west, the east, the north, the south, and the Centre. Historically, colours were used in formal attire to distinguish rank, title, and status in the imperial court. ${ }^{17}$ Traditional Chinese opera costumes, are mostly in accordance with this colour-coding, as they mainly involve ten colours. The Upper Five Colours include fully saturated red, green, yellow, white, and black, while the Lower Five Colours include maroon, pink, purple, light-blue, and olive-green. ${ }^{18}$ The upper colours are often used pure, while the lower colours can vary in shades. The most complex and expensive costumes are longpao (dragon robes) for emperors, nobilities, high-ranking military officers, and the kao (armour) worn by male and female warriors. Following the general cultural custom, Chinese Opera reserves golden-yellow for the roles of emperors and empresses. ${ }^{19}$ Other symbolic assignments of colours to different roles include orange for nobilities, red for respected figures, darker shades for mature characters, and lighter colours for the youthful roles. The colours are not gender-specific, yet a pure white dress with no pattern is designated for the roles of female ghosts and spirits, but white dragon robes are for dashing young generals, like Pinggui in the play of Baochuan - a favourite of Caridad's.

Opera actors have their own chests of costumes that accompany them from one place to another when they perform. Caridad used to have beautiful gowns and dresses given to her by visiting divas from San Francisco, but unfortunately lost them over the years and later had to make her own. In 1993, during the centennial celebration of Casino Chung Wah - the most significant Chinese community house in Cuba - Caridad and Georgina and other stage sisters performed Cantonese Opera after a thirty-six-year gap. During the event, many Cubans and Cuban-Chinese witnessed how Chinese theatre was performed in the 1950s by actresses of Cuban-Chinese descent. ${ }^{20}$ Their children and grandchildren finally were able to catch a glimpse of their unique art. By that point, the opera performance was a rather isolated event, not a recurring form of entertainment as it used to be. The older generations of Cuban-Chinese and visitors from Canton who were familiar with this artform, could tell that Caridad and Georgina's self-made costumes and headpieces were far from proper.

Chinese American photographer Lau Pok Chi was the first outsider to discover Caridad and Georgina's stories and to film them performing. Lau's short video, Cuban Chinese (2010), has a clip which is included in Havana Divas, showing them playing an episode of Baochuan in their 
home-made costumes. This play is based on a legend passed down from the $10^{\text {th }}$ century. Baochuan is the youngest daughter of the prime minister, who insists on marrying a handsome but poor young man of her choice against her father's will. To punish her, her father severs their bond and sends Pinggui to war. After 18 years, he finally comes back to her with high status earned from his courage and military traits. ${ }^{21}$

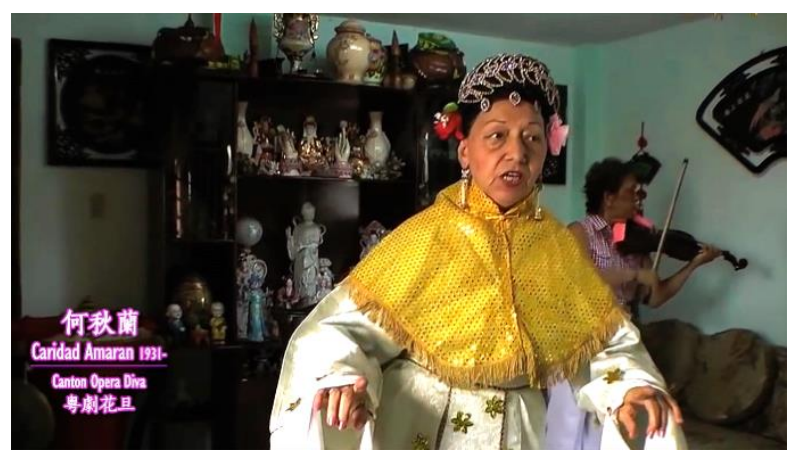

Figure 7: Caridad plays the role of Baochuan in Cuban Chinese (2010).

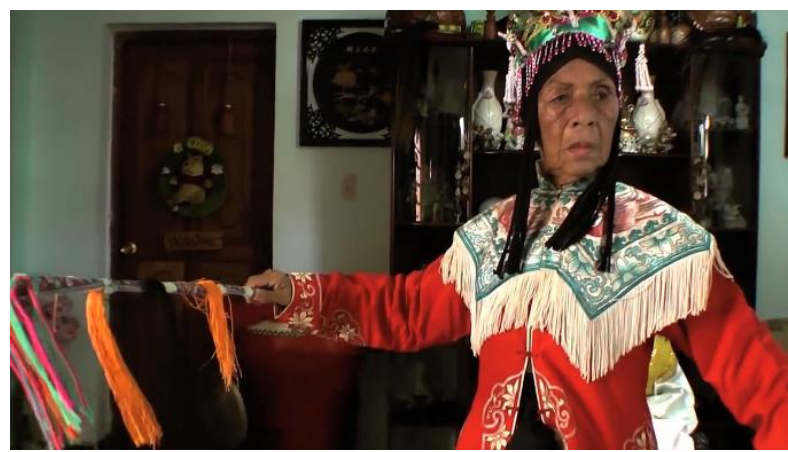

Figure 8: Georgina, who holds a horsewhip in the style of the opera prop, plays young general Pinggui in Cuban Chinese (2010).

Any opera fan can tell that the colours and styles of these costumes are all wrong and do not match the roles they play [Fig.7 and 8]. The plot requires two sets of contrasting costumes for Baochuan: before marriage, she wears a red dress with a red embroidered cape [Fig. 9] revealing her status; after marriage, she wears a simple black long jacket decorated with blue hemline over a white dress underneath to indicate her life in poverty. In the role of a young warrior, Georgina should wear white armour [Fig. 10] instead of an orange-red jacket [Fig. 8]. The opera shows sympathy to Baochuan and Pinggui by dressing them in the upper colours of red, black, and white. From Caridad's photos, we can see that even when playing Baochuan 60 years ago, she had on the same black jacket. In 2009 when the video was shot, Caridad and Georgina had only one set of costumes [Fig.7 and 8], which were not made for any particular role. When we saw the video, we were confused about the roles they played at first, but then understood their situation. 


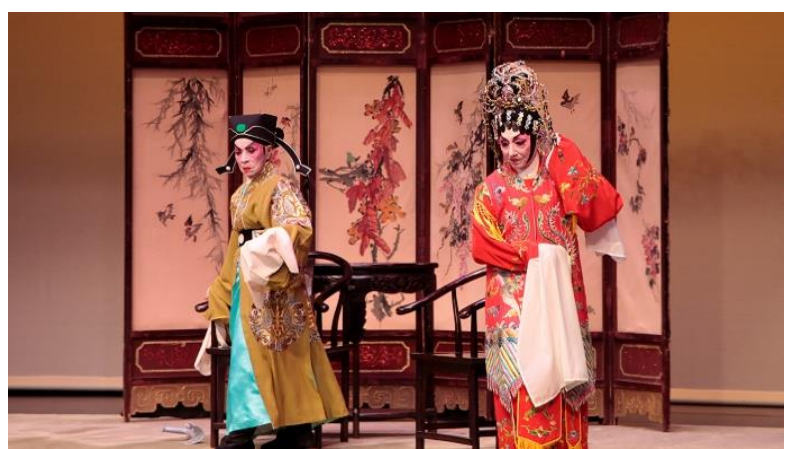

Figure 9: Caridad (right) and Georgina played the role of Baochuan and the prime minister in an episode of Baochuan.

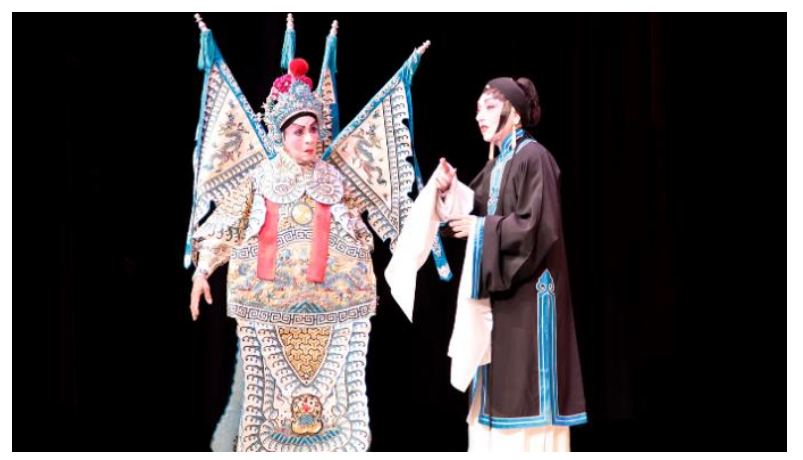

Figure 10: Caridad (right) plays Baochuan in poverty and Georgina her husband, Pinggui. Both photos are by Eugene Cheung and shot at Hong Kong Art Festival, 2019.

From Cuban Chinese, we can see that their makeup was far from "proper" either. Cantonese Opera has intricate facial paintings for formidable characters. Still, most roles only involve makeup with three colours - black, rouge, and a white oil-base, which is similar to the greasepaint makeup used in early black-and-white cinema, and functions in a similar way with the opaque grease erasing differences in complexion. ${ }^{22}$ Before opera makeup is applied, the hairline is wrapped by a black cloth, that is tied tightly around the head to pull both face's skin and eyebrow ends upward to give the face a lift. The white oil-base was designed to enhance facial visibility while lending the actors a look of otherworldliness. When applied to the Cuban divas, it erased the racial differences between Caridad and Georgina [Fig. 11]. 


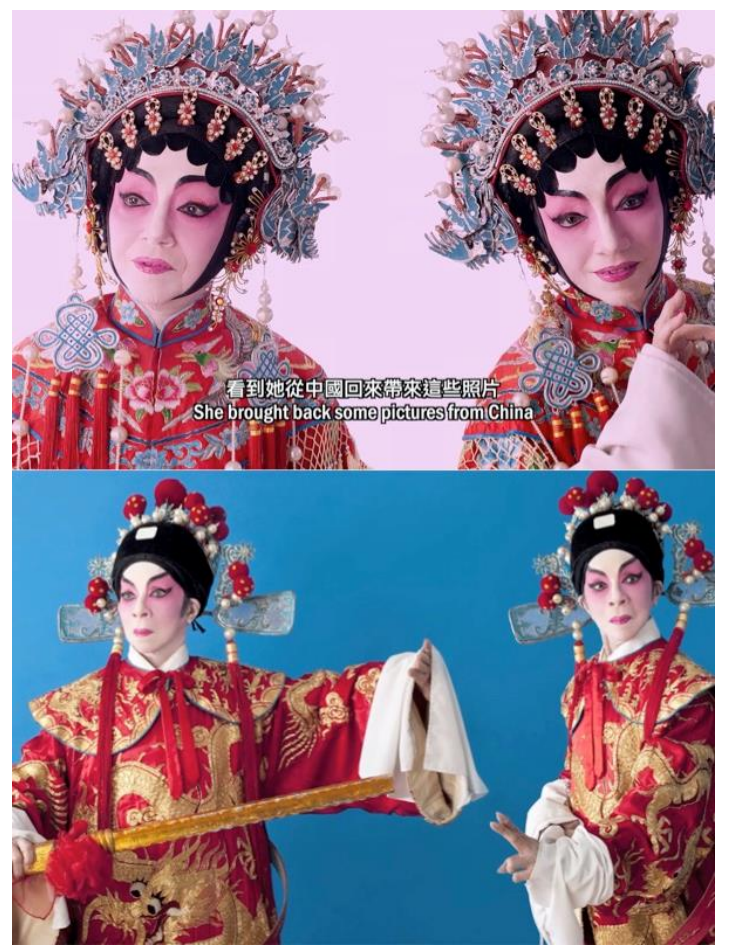

Figure 11: Caridad and Georgina tried on different costumes in their photos session in 2011.

The above photos were shot during their first trip to China in 2011, in a historical area called Zhuangyuanfang in Guangzhou city where the last opera costume factory with Canton-style embroidery remains in operation. ${ }^{23}$ Caridad and Georgina posed for former Vogue photographer Hilda Hsu with full opera makeup and in several sets of costumes. They were seventy-nine and eighty-one at the time, but their professional makeup and hair-setting restored their youth. I remember the gasp in the cinema when viewers saw these images on the big screen. The divas, oceans apart and half a century later, regain an eternal moment of glory and glamour in these photographs, which contribute to a new set of memories for them.

\section{Memory Is Never Monochromic}

The colour dynamics of both Cantonese Opera and Havana's cityscape are part of the two divas' lives and can be seen clearly from the footage we shot in Cuba and China between 2011 and 2019. To visualise their theatrical career from the 1930s to the 1960s as recounted by Caridad and Georgina, I relied on newsreels and photographs collected from archives, as well as the two divas. Black-and-white images account for about one-third of the entire film and are more concentrated in the first hour of the 96-minute film. During the postproduction, I had to make a decision whether or not to leave these black-and-white images untouched. I do appreciate the "powerful cultural connotations" within the "blackness"; what Tom Gunning calls "an aesthetic" of "the absence of color" in black-and-white films. ${ }^{24} \mathrm{I}$ also agree with his affirmation that in early cinema "the colors do not perform any obvious narrative or thematic function" or carry fixed meanings. ${ }^{25}$ These two affirmations, however, led to my decision not to leave any frame of the black-and-white images completely monochromic for a number of reasons.

Firstly, there is an enigma between the colourfulness of memory and its documentation in black-and-white. As discussed by Richard Misek, black-and-white was linked to "realism" rather than "spectacle" in early cinema and perceived as a "technological relic" when colour film became the norm in the 1960s. Misek examines several films produced between 1965 and 1983 that 
juxtapose black-and-white and colour sequences, where black-and-white is associated with, or created to mimic, documentary. ${ }^{26}$ Still having an influence today, this approach might result from the memory of watching wartime newsreels before features, which most of my interviewees over seventy remember. When recalling the past, they described their life events and emotions in vivid expressions and colourful languages that I find the monochromic (moving) images unable to represent.

Secondly, once the decision was made to add colour to the black-and-white images, my options were colourisation and tinting. We began with a careful examination of coloured photos of Caridad, which were hand-painted. We did try colourising a very clear photo of Caridad in opera costumes and daily fashion [Fig. 12 and 13], but the result was not ideal. It seems challenging to make the skin tone look natural on a black-and-white photo even with digital tools. ${ }^{27}$ Caridad has a couple of photographs taken in colour, but they are faded considerably.

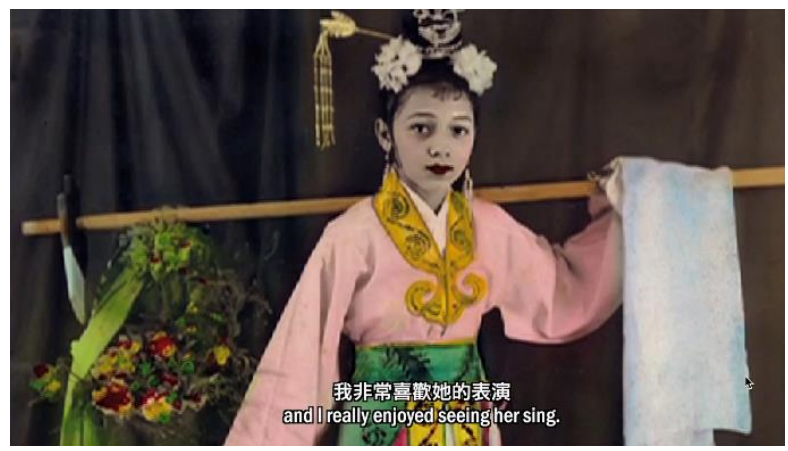

Figure 12: Caridad dressed as Lin Daiyu in a classic play titled "Dream of the Red Chambers," c. 1939.

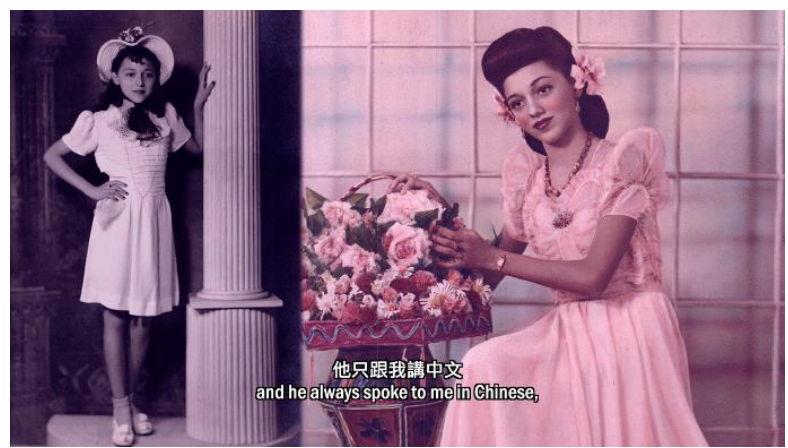

Figure 13: A still juxtapose Caridad at 14 (left) and 15 (right, coloured) in 1945 and 1946.

Among our newsreel footage from the 1940s, there were two colour films: a tourism documentary and a short film titled San Francisco Chinatown Rice Bowl Party (circa. 1941) by Joseph Sunn and C.R. Skinner. ${ }^{28}$ I could not possibly achieve the perfectly balanced and naturally looking colours in Sunn's film through colourisation, but I can get close to the effect of the tourism film shown in Figure 15 through tinting. 


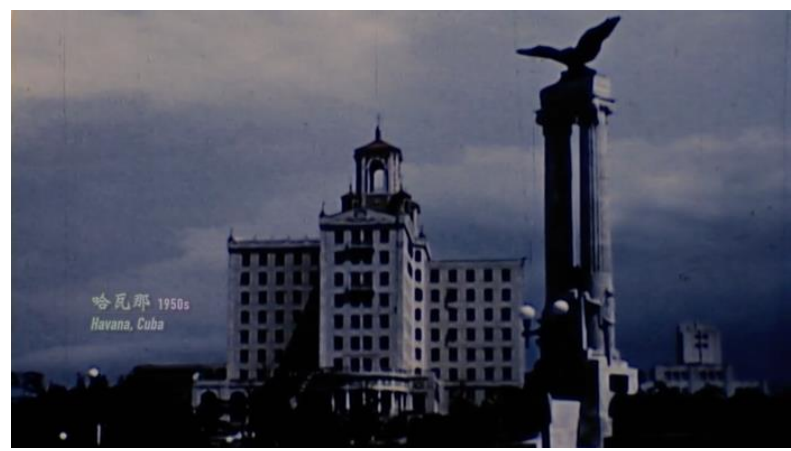

Figure 14: A still from a Havana tourism film shot in the 1904s.

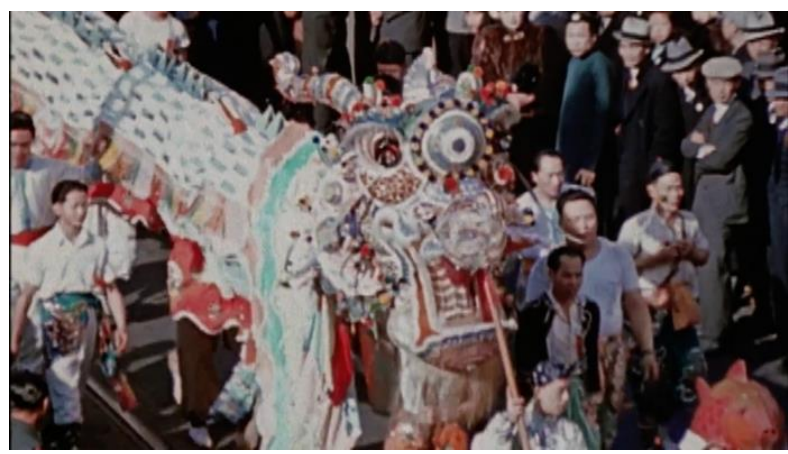

Figure 15: A still from San Francisco Rice Bowl Party (Joseph Sunn and C.R. Skinner, c. 1941) documenting the 79-days of the 1941 fund-raising campaign.

The last challenge lay in how to make tinted sequences work well with the rest of the film. Since scientists have already proved that there is no "universal preference" of colours for human psychology, we choose a tint for each period of Cuban history that the divas lived through, setting the basic emotional undertones according to their memory. ${ }^{29}$ We settled upon five colours for tinting. The dark history of the Chinese "coolies", who were captured, sold, and beaten on their way to Cuba in the prelude, followed by Caridad's early childhood years, are tinted in a purplish indigo [Fig. 16]. After Caridad and Georgina began to enjoy life in the prosperous Barrio Chino, the tint warms to light blue [Fig. 17 and 5]. Georgina described their opera years as a rosy dream, so images of their opera years are tinted in rose pink [Fig. 18]. Both Cuban and Chinese revolutionary palettes later resonated with Eisenstein's utilisation of red in his early works in Russia, which Misek describes as a "redness [used] to glorify and elicit a sense of pleasure in the rise of Communism". ${ }^{30}$ Thus newsreels of Castro's communist revolution and following sequences about Georgina's interrupted college life are tinted in maroon red [Fig. 19]. Images of Georgina and Caridad's happy family life were tinted an orange-beige [Fig. 4].

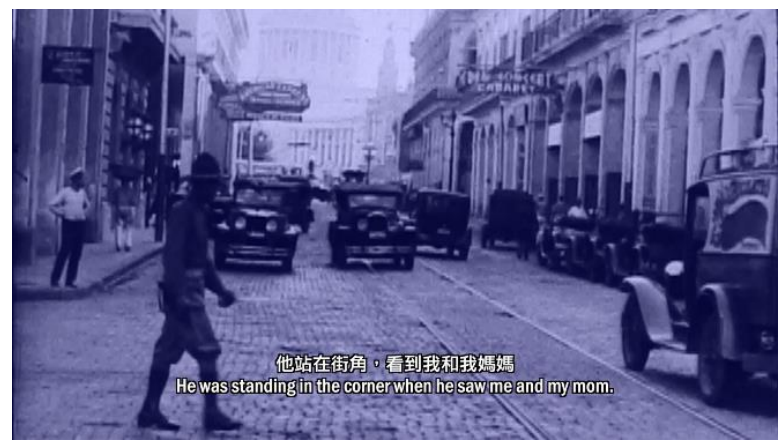

Figure 16: A frame tinged in indigo. 


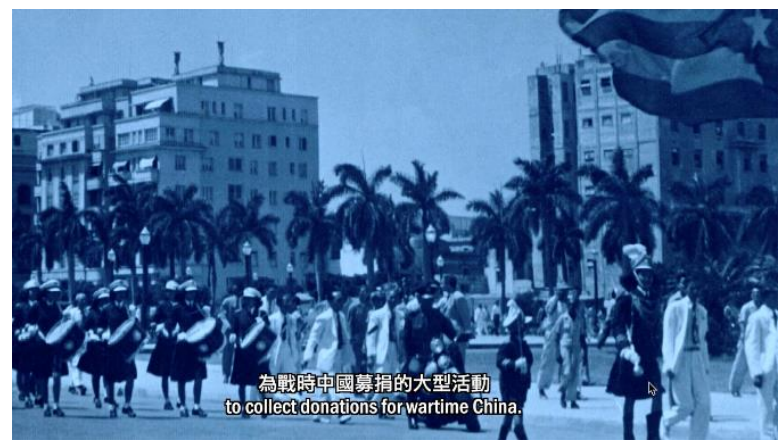

Figure 17: A frame tinged in Carolina blue.

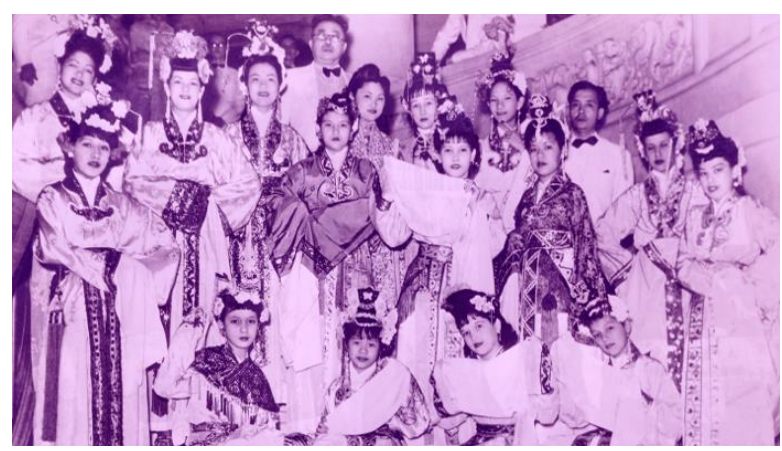

Figure 18: A frame tinged in rosy-pink.

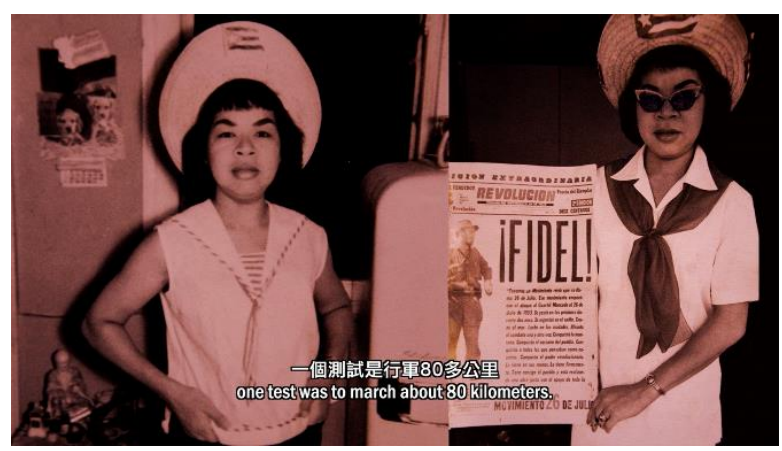

Figure 19: A frame tinged in maroon.

The five tints we applied - purple-indigo, light-blue, rose-pink, maroon-red, orange-beige - resonate with four of the Lower Five Colours of Chinese Opera costumes (pink, purple/indigo, maroon, and light-blue) and three colours of Havana's palette (pink, orange, and light-blue). In this manner, when one sequence transitions to the next, there is always at least one or two colours continuing from frame to frame. The tints brighten shades of grey in black-and-white images, reducing the contrast between the black-and-white areas of the image, and resulting in connected hues across the film. Edward Branigan explains this practice very well in his discussion of the aesthetics of colour harmonies. In our case, the transitions between tinted and coloured sequences can better provide what he calls "a route of least resistance for the movement of a perceiver's eye." 31 The overall transition of tint from cold to warm is a feeling we hope to pass on to the audience. As commented by a Hong Kong critic, in her review of the film, "the base color of Cantonese opera is warm", that is why it can console many homesick hearts. ${ }^{32}$ 


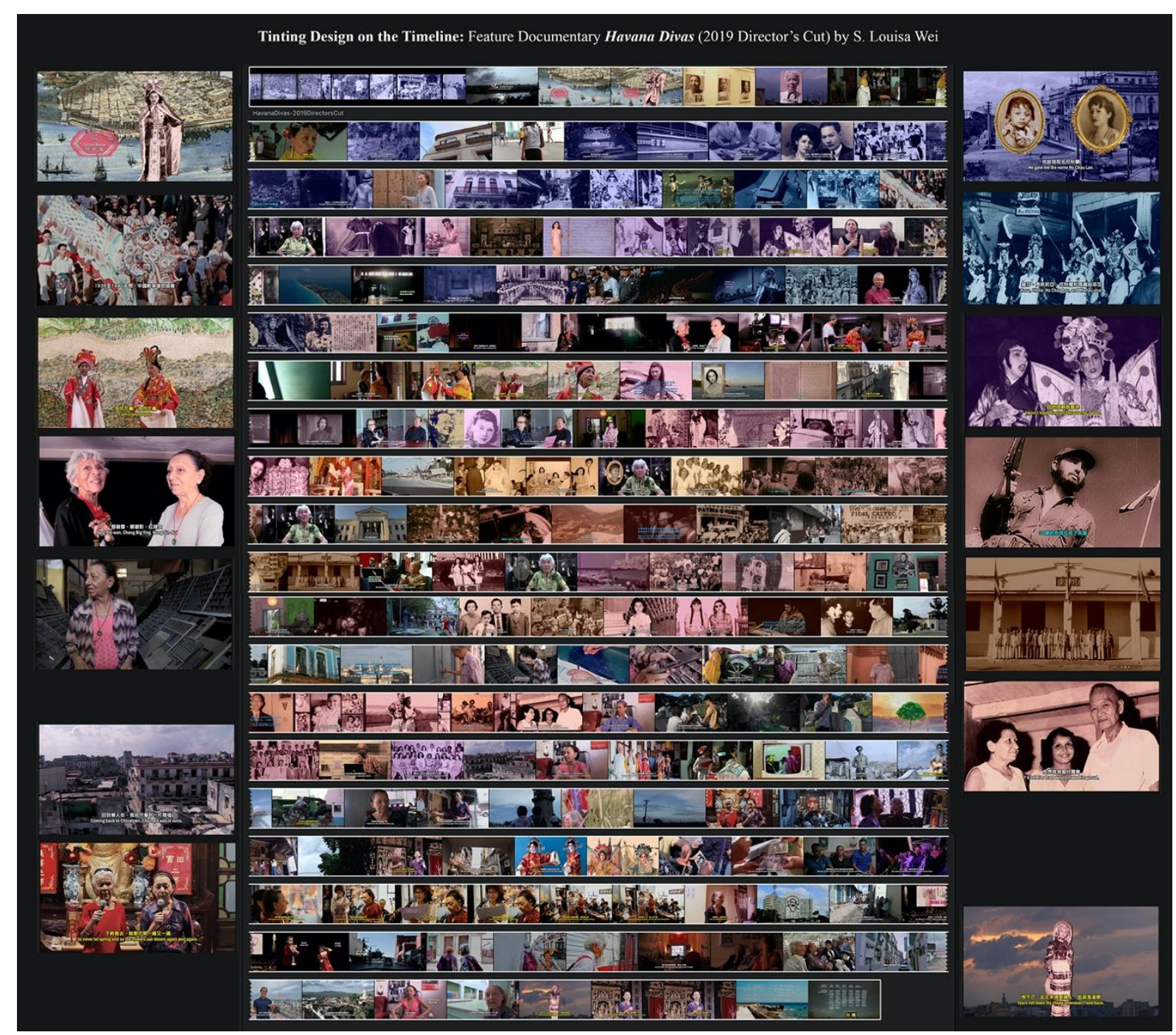

Figure 20: The middle part of this graphic shows a summary of the entire Havana Divas in a key-frame view. The stills lined up on the left, and the right respectively exemplifies coloured and tinted sequences.

The top left image and the bottom right image both have tinted silhouettes of Caridad in a coloured background, establishing a narrative closure.

One year after the premiere of Havana Divas around the Chinese New Year of 2018, more screenings followed in Hong Kong, and the divas finally performed at Yaumatei Theatre during the 2019 Hong Kong Art Festival. Caridad was eighty-eight and Georgina ninety. The hour-long performance included three episodes of Baochuan and dialogue with Lau Pok Chi sharing their life stories. Most members of the audience had read reports of their first two trips or had watched Havana Divas. This time, Caridad and Georgina had makeup artists, wardrobe assistants, and a full band playing a musical score that Caridad received from her father. Isolated for decades in Cuba, they have helped preserve a piece of Chinese cultural heritage that we might have forgotten. It was very touching to find fans waiting at the stage doors for them to come out of the dressing room. That was a moment evident to the divas' reclaiming of an identity that they had lost for sixty years. 


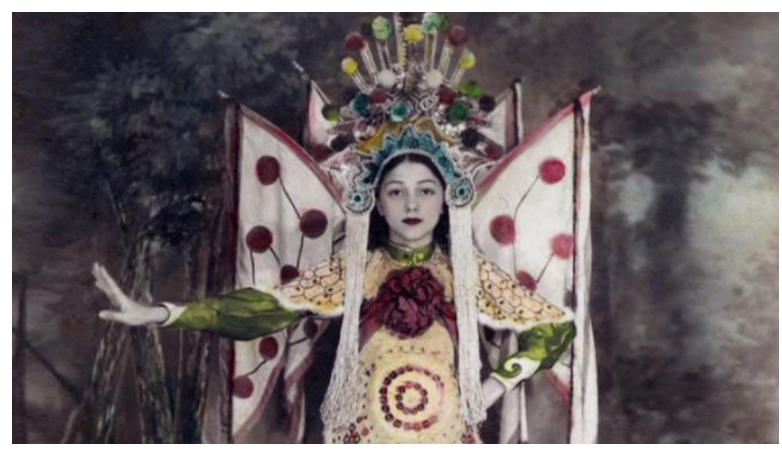

Figure 21: A coloured black-and-white photograph dated 1947 shows Caridad in a female warrior's armour, which is used on the film's poster.

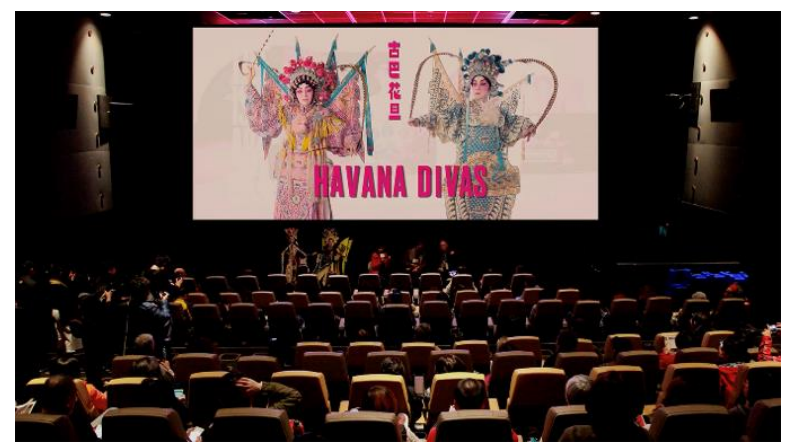

Figure 22: The world premiere of Havana Divas in Hong Kong's MOViE MOViE cinema on February 11, 2018.

Their three journeys to Canton between 2011 and 2019 were called home-comings by the media. ${ }^{33}$ Being treated as Chinese daughters in Canton has generated new memories for Caridad and Georgina. When I close my eyes, I can still see Caridad standing on the famous opera stage at Foshan's Ancestry Temple, singing about the passing of youth with her frail yet enduring voice.

*All figures courtesy of Blue Queen Cultural Communication Ltd.

\footnotetext{
${ }^{1}$ In 2015, according to Jorge Chou, the Spanish Secretary of Casino Chung Wah (the most prominent community house of Cuban Chinese), there were only about 120 first-generation Chinese immigrants left in Havana. Most of them were over 70 years old. Starting from the divas' generation, very few second-generation Cuban Chinese could speak or read Chinese. Casino Chung Wah is maintained with partial sponsorship from both the Cuban government and the Chinese Embassy.

${ }^{2}$ Eco, 1985, 157-159.

${ }^{3}$ Havana Divas was shot between 2011 and 2015 and first completed as a 90-minute feature film premiered on February 11, 2018, in "Life Is Art" Film Festival, Hong Kong. After a second trip to Havana in January 2019, the film was revised to include new footage. The 96-minutes "Director's Cut" was premiered on March 12, 2019, at Hong Kong Art Festival.

${ }^{4}$ Historians cite different numbers of the first wave of Chinese men between 1847 and 1874.1874 was the year when the Chinese government formally established embassies in Cuba to protect Chinese labourers. Narváez's number is $125,000(2005,869)$ and Treto's 150,000, $(2008,90)$.

5 Triana and Herrera, 2009, xii.

${ }^{6}$ Benton, 2007, 39-40.
} 


\footnotetext{
7 Rao, 2017, 8.

${ }^{8}$ Rao, 2017, 207-308.

9 Triana and Herrera, 2009, 114-115.

${ }^{10}$ Triana and Herrera, 2009, 115-116.

${ }^{11}$ Caridad told us this information with photographs as proof; Triana and Herrera also document this event (2009, 116).

${ }^{12}$ The "imperial colours" are named "Chinese red" and "yellow gold leaf" in the article by Chiu, Myers, and Goad on Jørn Utzon’s design (2020, 288-291).
}

13 Utzon, 2002, 59-60.

${ }^{14}$ Spectators wrote similar accounts of different places, see Rao, 2017, 8; England, 1922, 11; Triana and Herrera, 2009, 116; Thorpe, 2016, 124; Chua, 2019, 575.

15 Triana and Herrera, 2009, 116.

${ }^{16}$ Rao, 2017, 4.

17 Vollmer, 1980, 3-11.

18 Bonds, 2008, 73, 77, and 79; different names are used for lower five colours, for instance, bronze instead of "maroon," light-green for "olive green," Zhang, 1999, 9.

19 Zhang, 1999, 66, 20, and 34.

20 Triana and Herrera, 2009, 117.

${ }^{21}$ The legend of Baochuan has many versions beyond the initial plot set up described here. It inspired many operas in different regional forms, four motion pictures respectively made in 1939, 1956, 1959 and 1967, two TV series made in 1999 and 2012, as well as a 1950 English TV film and a 2017 book-both titled Lady Precious Stream. Even today, the legendary cave Baochuan lived in is still a tourist site in Xian, China.

22 Dootson's essay has a detailed discussion on the makeup invented for making the skin looking natural on Technicolor films $(2016,108)$. The oil-base for opera, even though very similar in texture, is mainly to enhance the visibility of actors' faces in all sorts of lightings.

${ }^{23}$ Jin, 2012, 39.

${ }^{24}$ Gunning, 88.

${ }^{25}$ Misek, 2010, 14-16.

${ }^{26}$ Misek, 2020, 4, 101.

${ }^{27}$ Misek, 2010, 102-109.

28 There is little documentation on this film. The title and the name of photographers are printed on the film. Joseph Sunn is better known as Joseph Sunn Jue (1904-87), who founded the Grandview film company in San Francisco in the 1930s. According to Law Kar and Frank Bren, in the 1940s, Grandview's black-and-white films were all shot on $35 \mathrm{~mm}$ but color films on $16 \mathrm{~mm}$ (83). My copy was from Oddball Films, a stock film company in San Francisco. A few clips from the film can be watched here: https://www.oddballfilms.com/clip/13161 12846 chinatown sf2

29 Taylor, Clifford, and Franklin, 2013.

${ }^{30}$ Misek, 2010, 23.

31 Branigan, 2018, 152. 
32 Wei, 2018, 42.

${ }^{33} \mathrm{Li}, 2018,10$.

\section{Bibliography}

Benton, Gregor. 2007. Chinese Migrants and Internationalism: Forgotten Histories, 1917-1945. New York and London: Routledge.

Branigan, Edward. 2018. Tracking Color in Cinema and Art: Philosophy and Aesthetics. New York: Routledge.

Bonds, Alexandra B. 2008. Beijing Opera Costumes: The Visual Communication of Character and Culture. Honolulu: University of Hawaii Press.

Chiu Chen-Yu, Peter Myers, and Philip Goad. 2020. "Chinese Colours and the Sydney Opera House (1956-1966): Jørn Utzon's Reinterpretation of Traditional Chinese Architecture" in Journal of Design History, 27(3), 278-296.

Chua, Soo Pong. 2019. "Chinese Performing Arts" in Chong Guan Kwa and Bak Lim Kua eds. A General History of the Chinese in Singapore. Singapore: Singapore Federation of Chinese Clan Associations.

Dootson, Kirsty Sinclair. 2016. “"The Hollywood Powder Puff War': Technicolor Cosmetics in the 1930" in Film History, 28:1, 107-131.

Eco, Umberto. 1985. "How culture conditions the colours we see" in M. Blonsky. Ed. On Signs. Oxford: Blackwell, 157-75.

England, Elizabeth Ann. 1922. "The Censor Comes to Mott Street" in The New York Herald, August 6, 11.

Gunning, Tom. 2013. 'Where Do Colors Go at Night?' In Color and the Moving Image, edited by Simon Brown, Sarah Street, and Liz Watkins, 81-92. New York: Routledge.

Jin, Xiangfu. 2012. "Shop Front, Factory Back: Zhuangyuanfang Opera Costume" [in Chinese] in Nanguo Hongdou, No.5, 39-42.

Jones, Loyd A. 1929. "Tinted Films for Sound Positives" in Transactions of the Society of Motion Picture Engineers 13 (37): 199-226.

Law, Kar, and Frank Bren. 2004. Hong Kong Cinema: A Cross-Cultural View. Lanham: Scarecrow Press Inc.

Li, Neil. 2018. "The Divas Come Home” in China Daily (Hong Kong Edition), April 13 (2018), 10. https://www.chinadailyhk.com/articles/27/20/22/1523586961605.html

Misek, Richard. Chromatic Cinema: A History of Screen Colour. West Sussex: Wiley-Blackwell, 2010. 
Narváez, Benjamín N. 2018. "Subaltern Unity? Chinese and Afro-Cubans in Nineteenth-Century Cuba” in Journal of Social History 51: 4 (2018), 869-898.

Parramón, José M. 1989. Colour Theory. New York: Watson-Guptill Publications.

Rao, Nancy Yunhwa. 2017. Chinatown Opera Theater in North America. Champaign: University of Illinois Press.

Sebryk, Karrie M. 1995. A History of Chinese Theatre in Victoria. Master Thesis. Victoria: University of Victoria, Canada.

Taylor, Chloe, Alexandra Clifford, and Anna Franklin. 2013. "Colour Preferences Are Not Universal" in Journal of Experimental Psychology: General, 142:4, 1015-1027.

Thorpe, Ashley. 2016. Performing China on the London Stage: Chinese Opera and Global Power, 1759-2008. London: Palgrave Macmillan.

Treto, Carlos Alzugaray. 2014. "Cuban-Chinese Relations after the End of the Cold War" in Catherine Krull ed. Cuba in a Global Context: International Relations, Internationalism, and Transnationalism. Gainesville, FL: University Press of Florida, 89-108.

Triana, Mauro Garcia, and Pedro Eng Herrera. 2009. Trans. and Ed. The Chinese in Cuba, 1847Now. Lanham: Lexington Books.

Utzon, Jørn. 2002. Sydney Opera House: Utzon Design Principles. Sydney: The Sydney Opera House Trust.

Vollmer, John E. Five Colours of the Universe: Symbolism in Clothes and Fabrics of the Ch'ing Dynasty (16441911). Edmonton, Alberta: The Edmonton Art Gallery, 1980.

Wei, Yulan. 2018. "Cuban Chinese and Lasting Opera" [in Chinese] in Asian International Weekly, 32:10, March 18 (2018), 42-43.

Zhang, Ming. 1999. Ed. Trans. Li Zhurun and Andrew McEwan. Costumes of Peking Opera. Beijing: Intercontinental Press.

\section{Filmography}

Sunn, Joseph, and C.R. Skinner. 1941. (photographers) San Francisco Chinatown Rice Bowl Party. Colour. Length not known.

Lau, Pok Chi. 2010. (director, producer) Cuban Chinese. Short, 23 minutes, HDV.

Wei, S. Louisa. 2019. (writer, director, editor) Havana Divas, feature documentary, 96 minutes, HD. Supported by the Hong Kong Art Development Council. Hong Kong: Blue Queen Cultural Communication Ltd.

Wei, S. Louisa. 2014. (writer, director, editor) Golden Gate Girls, feature documentary, 90 minutes, HD. Supported by the Hong Kong Art Development Council. Hong Kong: Blue Queen Cultural Communication Ltd. 


\begin{abstract}
About the Author
Louisa Wei is an Associate Professor at the City University of Hong Kong, a documentary filmmaker, and a member of the Hong Kong Director's Guild. She writes extensively on Chinese female directors and women's cinema, having published many articles, book chapters, encyclopaedia entries, and two books on the topic. Her two feature documentaries, Golden Gate Girls (2014) and Havana Divas (2018), respectively focusing on how Chinese language films and Cantonese operas travelled in North and Latin America from the 1920s to the 1960s. Both films have received positive reviews and reportage from major media like The Hollywood Reporter and BBC.
\end{abstract}

